\title{
Diacetyl nadolol: 3-month ocular hypotensive effect in glaucomatous eyes
}

\author{
EFRAIM DUZMAN, ${ }^{1}$ NACHUM ROSEN,${ }^{2}$ AND MOSHE LAZAR ${ }^{2}$ \\ From the ${ }^{1}$ Department of Ophthalmology, UCI College of Medicine, and Allergan Pharmaceuticals \\ Clinical Research Department; and the ${ }^{2}$ Department of Ophthalmology, Ichilov Medical Center, \\ Tel Aviv University, Israel
}

SUMMARY In a double-masked, 3-month clinical study the ocular hypotensive effects of diacetyl nadolol (DAN), timolol, and nadolol were compared. When applied topically to the eyes of glaucomatous patients timolol $0.5 \%$ was found to be significantly more effective than DAN $2 \%$ in controlling IOP at 3 of 10 evaluation periods. Fewer patients, however, developed tolerance to DAN $2 \%$ than to timolol $0.5 \%$. DAN $0.5 \%$ was also effective in lowering intraocular pressure in 3 of 8 patients tested. Nadolol $2 \%$ had no long-term ocular hypotensive effect. Two of 8 patients treated with DAN 2\% developed a bilateral periorbital dermatitis and were removed from the study even though their intraocular pressures were well controlled. No other clinically significant local or systemic side effects were observed during the course of the study.

Pharmaceutical research in glaucoma drug therapy is currently focused on beta-adrenergic antagonists and their clinical use in controlling raised intraocular pressure (IOP). Nadolol, a nonselective beta-blocker without intrinsic sympathomimetic action ${ }^{1}$ and currently available for the treatment of systemic hypertension ${ }^{23}$ and angina pectoris ${ }^{45}$ was tested for its ocular hypotensive activity. In one study on subjects with normal IOP topically applied nadolol in $2 \%$ concentration did not produce a substantial pressure reduction for periods longer than one week. ${ }^{6}$

Animal studies with radioactively labelled nadolol showed that very little of the topically applied drug was absorbed into the eye, suggesting that its poor clinical efficacy might be due to inadequate amounts of drug in the target tissues. Modification of the nadolol molecule was undertaken to increase its lipophilicity and thereby facilitate its transport through the cornea. Diacetyl nadolol (DAN) was produced by esterification of nadolol's 2 hydroxyl groups with acetate, and hydrolysis studies subsequently found it to be a prodrug analogue of nadolol.

DAN has been shown to lower IOP significantly when applied topically to glaucomatous eyes. In a 24-hour study on patients with raised IOP DAN 2\%

Correspondence to Efraim Duzman, MD, c/o Department of Ophthalmology, UCI College of Medicine. Irvine. California 92717. USA. and timolol $0.5 \%$ showed similar ocular hypotensive effects during the first 8 hours of treatment. ${ }^{7}$ Because this 24-hour study showed DAN to be effective without attendant side effects we decided to test the drug over a longer time period. This paper reports the results of a double-masked, 3-month clinical trial comparing the ocular hypotensive activities of DAN $0.5 \%$, DAN $2 \%$, nadolol $2 \%$, and timolol $0.5 \%$ in patients with chronic open-angle glaucoma or ocular hypertension.

\section{Subjects and methods}

\section{SELECTION OF PATIENTS}

The patients in this double-masked study were required to be at least 18 years old and to have binocular chronic simple glaucoma or ocular hypertension, with asymptomatic eyes otherwise. Informed consent was obtained from each patient after study procedures and risks were fully explained. Untreated intraocular pressure was required to be symmetrical $( \pm 5 \mathrm{mmHg})$ and at least $25 \mathrm{mmHg}$ or more in each eye. To determine suitability for inclusion in the study the candidates received a complete prestudy eye examination, auscultation of the heart and lungs, and an electrocardiogram.

Candidates with any of the following conditions or findings were excluded from the study: a corrected 
visual acuity of less than $20 / 80$ in either eye; a cup/disc ratio of more than 0.7 in either eye; abnormally low blood pressure or heart rate for their age; chronic obstructive pulmonary disease; greater than firstdegree heart block; a history of hypersensitivity to beta-blocking agents; currently receiving adrenergicaugmenting psychotropic drugs or steroid treatment; having been treated with systemic beta-blocking agents within the last 3 months.

\section{STUDY PROCEDURE}

After a washout period for all other ocular hypotensive drugs a baseline examination performed at the second study visit included a biomicroscopic and ophthalmoscopic examination of the eyes, a Schirmer test, a corneal sensitivity test, and measurements of IOP, visual acuity, pupillary diameter, blood pressure, and heart rate. In double-masked fashion the patients were randomly assigned to one of 4 treatment groups: nadolol $2 \%$, DAN $0.5 \%$, DAN $2 \%$, or timolol $0.5 \%$. They were instructed to instil one drop of masked test drug into each eye twice daily $(10 \mathrm{am}$ and $10 \mathrm{pm})$. No concomitant ocular medication was permitted.

At visits 3 through 12, corresponding to study days $3,7,14,21,28,35,42,56,70$, and 84 , study parameters that were measured at the baseline examination were again measured. On the examination days measurements were taken before the $10 \mathrm{am}$ drug instillation, and all monitoring was performed by the same investigator. Any patient who developed a drug-related side effect or had an IOP higher than or equal to baseline value at 2 consecutive visits was discontinued from the study. The latter of the 2 aforementioned criteria for discontinuance was used as the definition for 'uncontrolled IOP.' Correspondingly, any patient whose IOP was less than baseline value at a follow-up visit was considered to have their IOP controlled at that visit.

Statistical methods. Treatment groups were compared at baseline and at each follow-up visit (subtracting baseline values) by means of categorical data analysis and analysis of variance (ANOVA) techniques. IOP change is defined here as the change in IOP from the baseline value.

\section{Results}

The 4 treatment groups were not significantly different from each other with respect to distribution of age, sex, and race. The average age of the 31 subjects was 67 years. There were 18 male and 13 female subjects and all were Caucasian.

IOP CONTROL (Table 1; Figs. 1 and 2)

Nadolol $2 \%$. By the end of the fourth week all 8 patients receiving nadolol $2 \%$ were discontinued from the study because of uncontrolled IOP: one after the first week, an additional 5 after 2 weeks, one more after 3 weeks, and the last after 4 weeks. In patients who were well controlled the IOP changes ranged from +1.9 to $-2.0 \mathrm{mmHg}$ over a 21 -day period.

DAN 0.5\%. Three of 8 patients using DAN $0.5 \%$ maintained IOP reductions that were substantially lower than baseline values during the 3-month trial period. Five patients were discontinued at various points because of uncontrolled IOP: 3 after the second week, a fourth after the third week, and the fifth subject after the fifth week. In patients who were well controlled the IOP reductions ranged from -3.9 to $-7.8 \mathrm{mmHg}$.

DAN 2\%. One patient out of 8 treated with DAN $2 \%$ was discontinued after 4 weeks because of

Table 1 Mean IOP change from baseline among patients using one of 4 ocular hypotensive medications over an 84-day period $(\mathrm{mmHg})$

\begin{tabular}{|c|c|c|c|c|c|}
\hline \multirow[t]{2}{*}{ Day } & \multicolumn{4}{|l|}{ Treatment } & \multirow{2}{*}{$\begin{array}{l}\text { Analysis of variance } \\
\text { among treatments: } \\
\text { p value }\end{array}$} \\
\hline & $2 \% D A N$ & $2 \%$ Nadolol & $0.5 \%$ Timolol & $0.5 \% D A N$ & \\
\hline $1^{*}$ & $26 \cdot 6(8)$ & $26 \cdot 6(8)$ & $27 \cdot 6(7)$ & $27 \cdot 3(8)$ & NS \\
\hline 3 & $-8 \cdot 8(8)$ & $-0.6(8)$ & $-9 \cdot 1(7)$ & $-3 \cdot 9(8)$ & $<0.001$ \\
\hline 7 & $-8 \cdot 3(8)$ & $1.9(7)$ & $-8 \cdot 7(7)$ & $-5 \cdot 1(8)$ & $<0.001$ \\
\hline 14 & $-6 \cdot 1(8)$ & $-2 \cdot 0(2)$ & $-9.9(6)$ & $-6 \cdot 2(5)$ & $0 \cdot 03$ \\
\hline 21 & $-6 \cdot 9(8)$ & $0 \cdot 0(1)$ & $-9 \cdot 5(6)$ & $-6 \cdot 9(4)$ & 0.01 \\
\hline 28 & $-6 \cdot 8(7)$ & - & $-10 \cdot 0(6)$ & $-6 \cdot 0(4)$ & NS \\
\hline 35 & $-7 \cdot 9(7)$ & - & $-8 \cdot 2(6)$ & $-7 \cdot 3(3)$ & NS \\
\hline 42 & $-7 \cdot 6(6)$ & - & $-7 \cdot 8(6)$ & $-7 \cdot 8(3)$ & NS \\
\hline 56 & $-7 \cdot 3(6)$ & - & $-7 \cdot 2(6)$ & $-7 \cdot 8(3)$ & NS \\
\hline 70 & $-4 \cdot 7(6)$ & - & $-7 \cdot 8(5)$ & $-7 \cdot 5(3)$ & NS \\
\hline 84 & $-6 \cdot 2(5)$ & - & $-7 \cdot 4(5)$ & $-7 \cdot 8(3)$ & NS \\
\hline
\end{tabular}

*Baseline values: raw data means are given

NS= not significant.

Sample size in parentheses. 


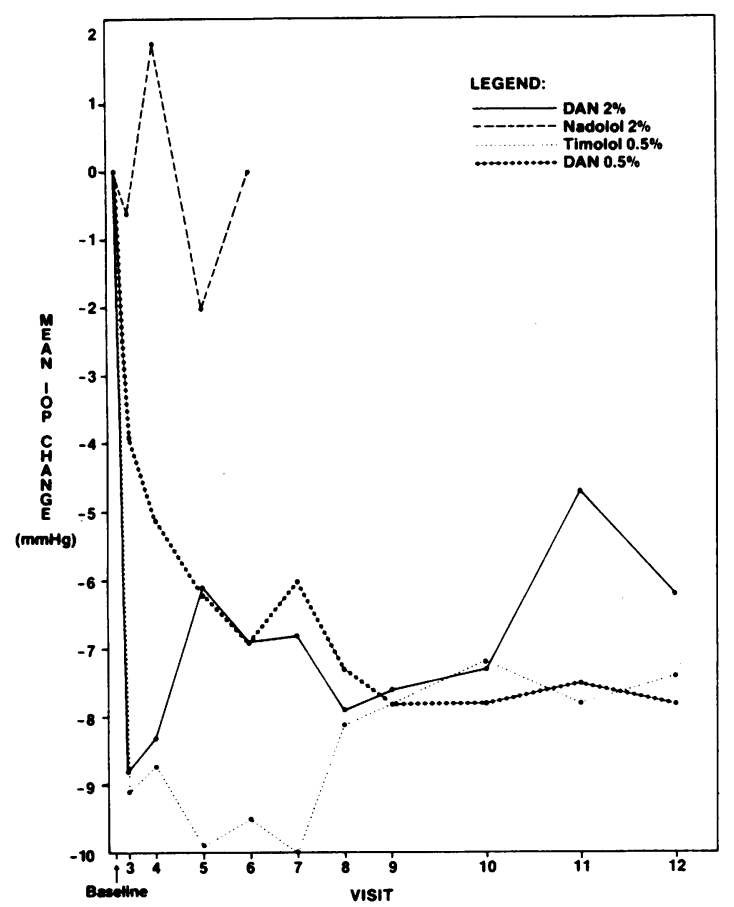

Fig. 1 Mean IOP change versus visit. (Mean IOP changes are averages of results obtained from both right and left eyes.)

inadequate IOP control. Two other patients were discontinued, one after 8 weeks and another during the twelfth week of treatment, because of a reaction diagnosed as periorbital dermatitis. The IOP of both patients, however, was well controlled up to the point of discontinuance. In the patients who were well controlled the range of IOP reduction was $-4 \cdot 7$ to $-8.8 \mathrm{mmHg}$.

Timolol $0.5 \%$. Five of 7 patients using timolol $0.5 \%$ proceeded throughout the entire trial with

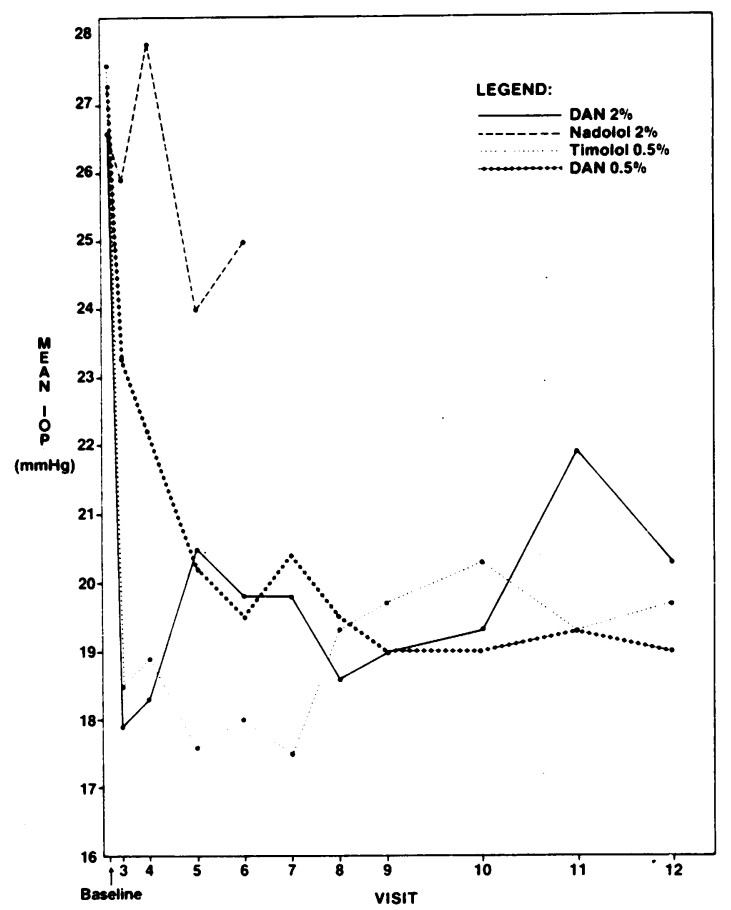

Fig. 2 Mean IOP in glaucomatous subjects receiving nadolol, DAN, or timolol over an 84-day period.

adequately controlled intraocular pressure. Two patients from the group were discontinued from the study because of uncontrolled IOP: one at the end of 2 weeks and the other after 10 weeks. In patients who were well controlled the drop in pressure ranged from $-7 \cdot 2$ to $-10 \cdot 0 \mathrm{mmHg}$.

SAFETY

There were no clinically or statistically significant changes in the heart rate, pupil size, and Schirmer

Table 2 Mean changes in systolic blood pressure from baseline among subjects using one of 4 ocular hypotensive medications over an 84-day period $(\mathrm{mmHg})$

\begin{tabular}{|c|c|c|c|c|c|}
\hline \multirow[t]{2}{*}{ Day } & \multicolumn{4}{|l|}{ Treatment } & \multirow{2}{*}{$\begin{array}{l}\text { Analysis of variance } \\
\text { among treatments: } \\
\text { p value }\end{array}$} \\
\hline & $2 \% D A N$ & $2 \%$ Nadolol & $0.5 \%$ Timolol & $0.5 \% D A N$ & \\
\hline $1^{*}$ & 140 & 144 & 140 & 149 & NS \\
\hline 3 & -4 & -10 & -10 & -6 & NS \\
\hline 7 & -2 & -4 & -12 & -10 & NS \\
\hline 14 & -3 & -7 & 2 & -18 & 0.06 \\
\hline 21 & -6 & -10 & -2 & -15 & NS \\
\hline 28 & -6 & - & 2 & -13 & NS \\
\hline 35 & -7 & - & 0 & -27 & 0.02 \\
\hline 42 & -7 & - & -7 & -23 & 0.05 \\
\hline 56 & -12 & - & -7 & -15 & NS \\
\hline 70 & -7 & - & -17 & 13 & NS \\
\hline 84 & -10 & - & -10 & -10 & NS \\
\hline
\end{tabular}

*Baseline values: raw data means are given. NS= not significant. 
Table 3 Mean changes in diastolic blood pressure from baseline among subjects using one of 4 ocular hypotensive medications over an 84-day period $(\mathrm{mmHg})$

\begin{tabular}{|c|c|c|c|c|c|}
\hline \multirow[t]{2}{*}{ Day } & \multicolumn{4}{|l|}{ Treatment } & \multirow{2}{*}{$\begin{array}{l}\text { Analysis of variance } \\
\text { among treatments: } \\
\text { p value }\end{array}$} \\
\hline & $2 \% D A N$ & $2 \%$ Nadolol & $0.5 \%$ Timolol & $0.5 \% D A N$ & \\
\hline $1^{*}$ & 83 & 86 & 84 & 86 & NS \\
\hline 3 & 2 & -3 & -3 & -4 & NS \\
\hline 7 & 3 & -5 & -4 & -6 & 0.07 \\
\hline 14 & -1 & -7 & -3 & -6 & NS \\
\hline 21 & 1 & -10 & -2 & -4 & NS \\
\hline 28 & 1 & - & -7 & 0 & 0.05 \\
\hline 35 & -2 & - & -3 & -2 & NS \\
\hline 42 & -3 & - & -3 & -2 & NS \\
\hline 56 & -1 & - & -6 & -8 & NS \\
\hline 70 & -5 & - & -7 & -5 & NS \\
\hline 84 & -3 & - & 0 & -10 & NS \\
\hline
\end{tabular}

*Baseline values: raw data means are given.

NS= not significant.

test results among or within treatment groups, nor were there any statistically significant changes in the test results for visual acuity and corneal sensitivity throughout the study.

The drop in mean systolic blood pressure in the DAN $0.5 \%$ group was clinically significant $(15 \mathrm{mmHg}$ or more) on days $14,21,35,42$, and 56 . This finding can be explained as an artefact resulting from patients with uncontrolled IOP dropping out of the study; because the remaining patients had lower systolic blood pressures initially, the drop in mean blood pressure is only apparent. Compared with the other treatment groups, the drop in systolic blood pressure in the DAN $0.5 \%$ group was statistically significant on days 14,35 , and 42 (Table 2). The only other clinically significant change in systolic blood pressure among the treatment groups was a drop that occurred in the timolol $0.5 \%$ group on day 70 . Changes in diastolic blood pressure among the treatment groups did not reach clinical significance (greater than 10 $\mathrm{mmHg}$ ), and no trends regarding increases or decreases were seen (Table 3 ).

Two patients in the DAN 2\% treatment group developed local sensitivity to the drug. The first of these 2 had treatment discontinued on day 56 because of an irritation appearing as a periorbital dermatitis, characterised by redness, excoriation, and scaling of the skin round the eyes, mainly in the lower lid areas. The bulbar conjunctivae were also congested, causing discomfort. Two to 3 days after drug was discontinued all eye and skin lesions disappeared. The patient was returned without symptoms to her prestudy treatment of timolol $0.5 \%$. Two months later she was again available for further investigation and was restarted on DAN 2\%. The cutaneous reaction did not reappear, and her IOP was well controlled for a $2^{1 / 2}-$-month period. At this point the local reaction, similar in character and distribution to the previous episode, recurred. The reaction signs again disappeared 3 to 4 days after discontinuation of the drug. The results of challenge with the vehicle, which contained all components of the formulation except for the active ingredient DAN, were negative, as were the results of skin sensitivity tests.

A similar problem arose in a second patient treated with DAN $2 \%$ approximately $2^{1 / 2}$ months after drug initiation. Up to that point the IOP had been well controlled, with no evidence of systemic or local side effects. The cutaneous reaction disappeared 3 to 4 days after treatment was discontinued. Retesting of this patient by applying DAN $0.1 \%$ and DAN $0.5 \%$ to the eyes, however, caused an immediate reappearance of the same cutaneous side effect. Results of challenge with the vehicle, which contained all components of the formulation except for the active ingredient DAN, were negative, as were the results of skin sensitivity tests.

\section{Discussion}

This 3-month study demonstrated the substantial and persistent reduction of intraocular pressure in a majority of patients treated with DAN $2 \%$. The ocular hypotensive effect of timolol $0.5 \%$ was significantly greater than that of DAN $2 \%$ at 3 of 10 evaluation periods, although discontinuation of treatment due to the development of drug tolerance was less frequent with DAN $2 \%$ than with timolol. Calculation of the mean IOP for the DAN 0.5\% group did not include the results from 5 patients who had to be dropped from the study because of uncontrolled IOP - exclusion on ethical grounds. At visits 8 through 11 the 3 patients in that treatment group who did experience well controlled IOP for the duration of the trial had reductions in IOP comparable to those in the DAN 2\% and timolol groups. These 3 patients 
probably are 'responders'-individuals with a high sensitivity to $\beta$-adrenergic blocking drugs.

The analysis of the IOP data was performed in a way to show that 'responders' may be controlled on lower concentrations of drug for a longer period of time. The increasing reduction of mean IOP in the DAN $0.5 \%$ group between days 7 and 42 is due to a corresponding attrition of 'nonresponders' during this interval. Therefore the reader must not be misled into assuming that the overall potency of DAN $0.5 \%$ is comparable to that of DAN $2 \%$ or timolol $0.5 \%$.

An ocular absorption study performed on New Zealand albino rabbits' eyes showed that more drug was absorbed into the eye after DAN application than after nadolol application.? We therefore expected a greater hypotensive effect following instillation of DAN. However, in a preliminary clinical trial a single-drop application each of DAN $2 \%$ and nadolol $2 \%$ showed similar ocular hypotensive effects over the 24-hour trial period. ${ }^{7}$

In contrast there was a marked difference in efficacy between nadolol and DAN in this 3-month trial. Patients tested with $2 \%$ nadolol quickly developed tolerance to the drug, and all 8 were discontinued from the study within one month because of poor IOP control. Only one patient treated with $2 \%$ DAN was discontinued for that reason, however.

In their studies on $\beta$-adrenergic receptor density in rabbit corneas and iris-ciliary bodies Neufeld and co-workers $^{8}$ found an increased density of $\beta$ receptors after topical treatment with timolol. If this increase occurs with all $\beta$-adrenergic blockers, a similar increase in receptor density would occur after the administration of nadolol and DAN. The similar short-term effects and different long-term effects of nadolol and DAN that were observed may then be explained on the basis of a change in $\beta$-adrenergic receptor density over time.

In the single-dose situation the test concentration of nadolol was perhaps just sufficient to block all $\beta$-adrenergic receptors in the eye. Because of DAN's greater lipophilicity a greater concentration of drug than was needed to accomplish complete receptor blocking may have occupied the target tissue; if so, a surplus amount of drug was present at that point. If the number of receptors increased with prolonged exposure to DAN, the amount of drug that was supposedly surplus before that may then have been used to block the increased number of receptors, thereby maintaining IOP control. The concentration of nadolol that may have been sufficient to occupy the original number of receptors might eventually have become insufficient to block the increased number of receptors present after prolonged exposure, and incomplete receptor blocking would then have become translated into diminished IOP control.
Cutaneous side effects in patients on either systemic or topical $\beta$-blockers have previously been reported for practolol, ${ }^{9}$ propranolol, ${ }^{10}$ metoprolol,,${ }^{11}$ timolol, ${ }^{12}$ and oxprenolol. ${ }^{13}$ In this study the cases of periorbital dermatitis experienced by 2 of the patients in the $2 \%$ DAN treatment group were similar to each other in external manifestation but seemed to differ in pathogenesis. The first patient, when rechallenged with $2 \%$ DAN after a period off the drug, did not experience any immediate irritation. Adverse skin reactions did not reappear until $2^{1 / 2}$ months after DAN treatment had been started again. This response is not typical of an allergic reaction, and it might possibly have been due to direct irritation by the drug. The second patient, on the other hand, showed a reaction more characteristic of allergy in having an immediate reappearance of the skin reaction after re-exposure to low concentrations of DAN. This reaction appears to be a response to DAN rather than to some other component of the formulation, because neither patient experienced a reaction following application of the vehicle, which contained every component of the formulation except DAN.

Although DAN shows potential for broad use as an antiglaucoma agent, occurrence of the periorbital side effect is a source of concern. The nature of the mechanism producing this local skin reaction, whether it is an allergic reaction to the drug or the result of a direct irritation by DAN, and the incidence of this side effect in a larger test population are issues for future investigation.

The authors thank Judith Simon and Mary Jane Branin for their help in preparing the manuscript.

\section{References}

1 Lee RJ, Evans DB, Sherrin HB, Laffan RJ. Pharmacology of nadolol (SQ 11725), a $\beta$-adrenergic antagonist lacking direct myocardial depression. Eur J Pharmacol 1975; 33: 371-82.

2 Volicer L, Liang CS, Gavras H, Tifft C, et al. Effect of nadolol in treatment of hypertension. J Clin Pharmacol 1979; 19: 137-47.

3 Hitzenberger G. Initial experience with a new long-acting betablocker, nadolol, in hypertensive patients. J Int Med Res 1979; 7: 33-8.

4 Prager G. Angina pectoris; effective therapy once daily. J Int Med Res 1979; 7: 39-44.

5 Ling ASC, Groel JT. Improved physical performance as a therapeutic objective in patients with angina. BrJ Clin Pharmacol 1979; 7 (suppl 2): 161S-6S.

6 Duzman E. One-month double-masked study to evaluate the effect of $2 \%$ nadolol and placebo on intraocular pressure of normal volunteers. Data on file, Ophthalmic Clinical Research Department, Allergan Pharmaceuticals, Inc., 1979.

7 Duzman E. Anderson J, Blumenthal M. Diacetylnadolol. Part I-ocular pharmacology and short-term ocular hypotensive effect in glaucomatous eyes. Arch Ophthalmol 1982; 100: 1916-9.

8 Neufeld AH, Zawistowski KA. Page ED. Bromberg BB. Influences on the density of $\beta$-adrenergic receptors in the cornea 
and iris-ciliary body of the rabbit. Invest Ophthalmol Visual Sci 1978; 17: 1069-74.

9 Felix RH, Ive FA, Dahl MGC. Cutaneous and ocular reactions to practolol. Br Med J 1974; iv: 321-4.

10 Jensen HA. Mikkelsen HI, Wadskov S, Sondergaard J. Cutaneous reactions to propranolol (Inderal). Acta Med Scand 1976; 199: 363-7.
11 Neumann HAM, van Joost T, Westerhoff W. Dermatitis as side effect of long-term metoprolol. Lancet 1979; ii: 745.

12 Wind CA. Acute allergic reaction to timolol. Glaucoma 1981; 3: 56-8.

13 Leonard JC. Oxprenolol and a psoriasis-like eruption. Lancet 1975 ; i: 630 . 